\title{
PEMBUATAN METIL ESTER DARI MINYAK KEMIRI SUNAN DENGAN KEBERADAAN CO-SOLVENT ASETON DAN KATALIS HETEROGEN NATRIUM SILIKAT TERKALSINASI
}

\author{
Muhammad Yusuf Ritonga, Mangunsong Ruben Reinhard Giovani* \\ Departemen Teknik Kimia, Fakultas Teknik, Universitas Sumatera Utara \\ Jalan Almamater,Medan, 20155, Indonesia \\ *Email : rubengiovanisimangunsong@ gmail.com
}

\begin{abstract}
Abstrak
Metil ester dapat diproduksi dari minyak nabati maupun minyak hewani melalui proses transesterifikasi. Masalah yang sering timbul dalam proses transesterifikasi adalah waktu reaksi yang lama karena kelarutan minyak dan alkohol yang rendah dan pemisahan dan pemurnian katalis yang sulit dengan katalis homogen. Penambahan co-solvent dapat membantu pencampuran reaktan dan pemakaian katalis heterogen dapat mengatasi masalah katalis homogen. Minyak kemiri sunan memiliki nilai asam lemak bebas (ALB) yang tinggi sebesar 9,1517\% sehingga dilakukan pretreatment dengan esterifikasi sehingga bahan baku memiliki ALB 1,0538\%. Produk hasil esterifikasi ini dila njutkan dengan transesterifikasi untuk memproduksi metil ester dan gliserol. Metilester yang dihasilkan pada lapisan atas dipisahkan dari gliserol dan kemudian dicuci. Pengaruh dari berbagai yang variabel proses diamati dalam percobaan ini. Sifat-sifat metil ester seperti, densitas, viskositas, bilangan iodin, bilangan asam dan kadar metil ester, trigliserida, digliserida, dan monogliserida yang dibandingkan dengan Standar Nasional Indonesia (SNI) dan European Starndart (EN). Pada penelitian ini, kondisi yield terbaik diperoleh pada pengunaan katalis 3\%, co-solvent $20 \%$, waktu 30 menit dan suhu $40^{\circ} \mathrm{C}$ sebesar $96.1493 \%$. Hasil yang diperoleh pada penelitian ini menunjukan bahwa minyak kemiri sunan sangat cocok digunakan sebagai bahan baku pembuatan metil ester.
\end{abstract}

Kata kunci: metil ester, minyak kemiri sunan, esterifikasi, transesterifikasi, katalis heterogen

\begin{abstract}
Methyl ester can be produced from vegetable oil or animal oil through transesterification process. The problem that often arises in the transesterification process is the long reaction time because of oil and alcohol are not mutually dissolve and also separation and purification catalysts are difficult to homogeneous catalysts. The addition of co-solvent may assist the mixing of the reactants and the use of heterogeneous catalysts can overcome the problem of homogeneous catalysts. Sunan candlenut oil contained high free fatty acid (FFA) content of 9.1517\% so it needs to be pretreated by esterification so that the raw material has a $1.0538 \%$ FFA. The product from this stage was subjected to produce methylester and glycerol. The produced methyl ester on the upper layer was separated from the glycerol and then washed. Effect of various process variables were investigated. The propertiesof methyl ester like methyl ester content, density, viscosity, iodine value, acid value, the content of methyl ester, triglycride(TG), diglyceride(DG) and monoglyceride $(M G)$ was evaluated and was found to compare well with Indonesian Standard (SNI) and European strandart (EN). On this work the best yield condition, was obtain by using amount of catalyst $3 \%$ at $40^{\circ} \mathrm{C}$, for reaction time 30 minute in presence of $20 \%$ co-solvent of the 96,1493 yield methyl ester. The result of this work showed that sunan candlenut oli is very suitable as the feedstock of methyl ester.
\end{abstract}

Keyword: methyl ester, sunan candlenut oil, esterification, transesterification, heterogenous catalyst

\section{Pendahuluan}

Bahan bakar minyak bumi diperkirakan akan habis jika dieksploitasi secara besar besaran. Menurut prediksi dari World Energy Forum, cadangan dari bahan bakar minyak bumi, batubara dan gas alam akan habis kurang dari 10 dekade dengan tingkat komsumsi minyak dunia mencapai 85,4 juta barel minyak per hari. Ketergantungan terhadap bahan bakar minyak bumi dapat dikurangi dengan cara memanfaatkan bahan bakar biodiesel (metil ester), dimana bahan bakunya masih sangat besar untuk dikembangkan $[10,13]$.

Ada banyak sumber bahan baku yang tersedia untuk produksi biodiesel, tetapi $95 \%$ diantaranya diproduksi secara luas dengan menggunakan minyak nabati pangan. Dimana penggunaan minyak nabati pangan akan memacu masalah kemandirian pangan. Untuk 
meminimalkan masalah tersebut maka diperlukan sumber alternatif seperti minyak nabati non pangan [1]. Kemiri Sunan (Reutealis trisperma (blanco) airy shaw) merupakan tanaman yang dapat menghasilkan minyak nabati, yang bukan merupakan penghasil minyak makan karena mengandung racun [2].

Katalis homogen dapat dengan baik mengkatalitik proses transesterifikasi, namun dibandingkan katalis homogen, katalis heterogen mempunyai keunggulan dalam pemisahannya. Natrium silikat merupakan salah satu dari katalis heterogen dimana natrium silikat mempunyai toleransi terhadap FFA hingga sebesar 2,5\% dan juga toleransi terhadap air hingga sebesar 4\% [11, 12, 20].

Dalam memproduksi metil ester, salah satu masalah yang timbul adalah keterbatasan transfer massa dimana kelarutan minyak dalam metanol sangatlah rendah. Strategi mengatasi keterbatasan transfer massa tersebut adalah dengan reaksi satu fase. Reaksi satu fase tersebut dapat dibentuk dengan menambahkan solvent yang dapat meningkatkan kelarutan minyak, solvent tersebut dapat juga disebut co-solvent [19].

Aseton merupakan salah satu jenis cosolvent pada reaksi transesterifikasi. Aseton memiliki kepolaran menengah, sehingga diklasifikasikan sebagai aprotic solvent, oleh karena itu dapat larut dengan baik pada trigliserida (polaritas rendah) dan metanol (polaritas tinggi) [17].

Dengan mempertimbangkan hal tersebut, maka perlunya dilakukan pembuatan metil ester dengan minyak kemiri sunan dengan keberadaan co-solvent aseton dan katalis natium silikat terkalsinasi.

\section{Teori}

Biodiesel merupakan bahan bakar diesel yang berasal dari minyak nabati atau hewani yang dapat bekerja pada mesin diesel konvensional, sekalipun tanpa perlu ada modifikasi apapun dengan penambahan bahan pelindung [9]. Pemakaian biodiesel dapat mereduksi emisi dari $\mathrm{SO}_{\mathrm{x}}, \mathrm{CO}$, dan masalah partikulat hidrokarbon dalam gas buang dibandingkan bahan bakar diesel biasa [27].

Kemiri sunan (Reutealis trisperma (Blanco) Airy Shaw) berasal dari Filipina dan telah berkembang di Indonesia secara alamaiah di antaranya di daerah Jawa Barat dengan suhu udara berkisar antar $18-20^{\circ} \mathrm{C}$. Kemiri sunan juga dapat hidup di daerah dataran rendah sampai ketinggian diatas 100 $\mathrm{m}$ diatas permukaan laut [18].
Berdasarkan hasil ekstraksi minyak kemiri sunan diperoleh rendemen minyak yang berkisar 36,53 - 50 persen [18]. Bahkan Carlos Martin et al (2010) mendapatkan bahwa minyak kemiri sunan memiliki kadungan minyak sebesar $62 \%$ dimana jarak pagar hanya mengandung $49,1 \%$ dari berat bijinya [6]. Jika ditinjau dari potensi biji, produktivitas biji kemiri sunan dapat mencapai 12 ton/ ha/ tahun, dimana lebih besar dari jarak pagar yang hanya mencapai 10 ton/ ha/ tahun [3].

Minyak kemiri sunan tersusun dari beberapa asam lemak yang dapat diolah lebih lanjut menjadi berbagai produk oleokimia bernilai tinggi, akan tetapi minyak kemiri sunan mengandung racun sehingga tidak dapat dikomsumi dimana racun yang terkandung berupa senyawa asam $\alpha$-eleostearat dengan kandungan sebesar 50\% [18].

Reaksi satu fase dapat dibentuk dengan menambahkan solvent yang dapat menambahkan kelarutan minyak yang disebut juga sebagai co-solvent [19]. Co-solvent akan mengubah sistem reaksi dua fase menjadi satu fase, karena co-solvent mampu melarutkan dengan sempurna baik alkohol maupun trigliserida. Co-solvent sebisa mungkin mempunyai titik didih yang dekat dengan titik didih alkohol, sehingga bisa dipisahkan bersama-sama dengan alkohol setelah reaksi berakhir [22]. Keuntungan penggunaan cosolvent adalah co-solvent dalam reaksi dapat meningkatkan kelarutan minyak dan alkohol pada temperatur yang rendah [27] dan juga mempercepat reaksi [22].

Berdasarkan penelitian yang dilakukan Maeda.Y et al pada tahun 2010, aseton merupakan co-solvent terbaik dalam produksi biodiesel. Aseton merupakan salah satu jenis co-solvent pada reaksi transesterifikasi. Aseton memiliki momen dipol sebesar 2,88 D, dimana ini diklasifikasikan sebagai aprotic solvent [17].

\section{Metodologi Percobaan Bahan}

Bahan yang digunakan dalam penelitian ini adalah berupa minyak kemiri sunan yang diambil dari tempat kabupaten Sumedang, Jawa Barat, natrium silikat, aseton, asam sulfat, metanol dan air. Penelitian dilakukan di Laboratorium Proses Industri Kimia, Departemen Teknik Kimia, USU, Medan.

\section{Prosedur Kerja \\ Pre-treatment Bahan Baku}

Tujuan utama dari esterifikasi menggunakan katalis asam adalah untuk 
mengurangi kadar asam lemak bebas dalam minyak. Kadar asam lemak bebas dalam minyak harus kurang dari $2,5 \%$ sehingga memudahkan reaksi transesterifikasi. Reaksi esterifikasi dilakukan dalam reaktor batch. Minyak dituangkan ke dalam labu dan dipanaskan. Untuk ini, katalis asam $(1 \mathrm{~b} / \mathrm{b} \%)$ $\mathrm{H}_{2} \mathrm{SO}_{4}$ ditambahkan, diikuti oleh metanol dan reaksi dilakukan selama 1 jam. Perbandingan mol metanol / minyak adalah

9:1 dan suhu reaksi $60^{\circ} \mathrm{C}$ dipilih berdasarkan penelitian dari S.G Bojan dan S.K Durairaj [24]. Lalu metanol berlebih dipisahkan dengan rotary evaporator. Minyak hasil esterifikasi di cuci lalu di keringkan dioven pada suhu $105^{\circ} \mathrm{C}$ lalu minyak hasil esterifikasi di periksa kadar asam lemak bebasnya.

\section{Preparasi Katalis}

Katalis didehidarsi didalam oven pada suhu $200^{\circ} \mathrm{C}$ selama $15-20$ menit dan setelah itu dikalsinasi didalam muffle furnace pada suhu $400^{\circ} \mathrm{C}$ selama 2 jam [12].

\section{Proses Transesterifikasi}

Proses transesterifikasi dilakukan didalam reaktor batch. minyak hasil pretreatment di sebanyak 40 gram dicampurkan dengan sejumlah aseton dengan variasi $(10 \%$, $20 \%$, 30\%) lalu diaduk selama 30s dengan magnetic stirrer. Lalu campuran katalis berbagai variasi $(1 \%, 3 \%, 5 \%)$ dan metanol 6:1 dari berat minyak dimasukkan kedalam erlenmeyer lalu direaksikan dengan suhu bebagai variasi $\left(30^{\circ} \mathrm{C}, 40^{\circ} \mathrm{C}, 50^{\circ} \mathrm{C}\right)$ dan waktu bebabagai variasi (10, 30 dan 50 menit). Setelah reaksi siap katalis dan co-solvent dipisahkan dengan filtrasi vakum dan rotary evaporator. Campuran metil ester dan gliserol dipisahkan dalam corong pemisah lalu metil ester yang didapat dicuci untuk menghilangkan impuritis dan dikeringkan dalam oven pada suhu $105^{\circ} \mathrm{C}$.

\section{Analisis Fatty Acid Methyl Ester (FAME)}

Komposisi dari masing-masing metil ester ditentukan menggunakan kromatografer gas yang dilengkapi dengan detektor ionisasi api dan injektor auto.

\section{Analisis Lainnya}

Densitas (ISO 3507), viskositas kinematik (ATM D-445), Bilangan asam dan FFA (ISO 660), bilangan iodin (ASTM D1959) dari masing-masing metil ester dievaluasi dan dibandingkan dengan standar SNI dan EN $[4,5,14,15]$.
Hasil

\section{Analisa Bahan Baku}

Bahan baku minyak kemiri sunan ini dianalisis dengan menggunakan GC (Gas Chromatography) untuk mengetahui komposisi asam lemak yang terkandung didalamnya.

Berdasarkan data komposisi asam lemak dari minyak kemiri sunan dari data pada Tabel 1 dapat dilihat bahwa minyak kemiri sunan mengandung 26,0941\% asam lemak jenuh dan $74,9059 \%$ asam lemak tak jenuh. Dari kandungan asam lemak tersebut maka dapat ditentukan berat molekul minyak kemiri sunan (dalam bentuk trigliserida) adalah sebesar $870,0246 \mathrm{gr} / \mathrm{mol}$ sedangkan berat molekul FFA minyak kemiri sunan adalah sebesar 277,326gr/mol.

Tabel 1. Komposisi Asam Lemak Minyak Kemiri Sunan

\begin{tabular}{|c|c|}
\hline Komponen Penyusun & $\begin{array}{c}\text { Komposisi } \\
\mathbf{\%}(\mathbf{b} / \mathbf{b})\end{array}$ \\
\hline Asam Laurat (C12:0) & 0.0473 \\
Asam Miristat (C14:0) & 0.1329 \\
Asam Palmitat (C16:0) & 16.9349 \\
Asam Palmitoleiat (C16:1) & 0.8002 \\
Asam Stearat (C18:0) & 7.6561 \\
Asam Oleat (C18:1) & 38.6318 \\
Asam Linoleat (C18:2) & 35.0184 \\
Asam Linolenat (C18:3) & 0.2026 \\
Asam Arakidat (C20:0) & 0.3227 \\
Asam Eikosenoat (C20:1) & 0.2630 \\
\hline
\end{tabular}

Pada dalam penelitian tidak ditemukan asam $\alpha$-eleostearat hal ini disebabkan oleh asam $\alpha$-eleostearat yang dapat terkonjugasi menjadi asam linoleat [8], dimana dapat dilihat kandungan asam linoleat yang tinggi sebesar $35,0184 \%$. Hal ini juga sama seperti yang didapatkan oleh carlos martin et al (2010) dimana terdapat tiga asam lemak dominan pada minyak kemiri sunan yaitu asam palmitrat, oleat dan linoleat [6].

\section{Tabel 2. Sifat Fisika Dan Kimia dari} Minyak Kemiri Sunan

\begin{tabular}{|c|c|}
\hline Sifat Fisika & Jumlah \\
\hline Densitas & $0,9315 \mathrm{~kg} / \mathrm{m}^{3}$ \\
Viskositas & $69,5747 \mathrm{~mm}^{2} / \mathrm{s}$ \\
FFA & $9,1517 \%$ \\
\hline
\end{tabular}

Selain mengidentifikasi komponen asam lemak dalam minyak kemiri sunan dilakukan juga identifikasi sifat fisika dan kimia dari minyak kemiri sunan seperti densitas, viskositas dan kadar FFA. Data-data yang telah diperoleh akan disajikan dalam Tabel 2.

Dari Tabel 2 terlihat bahwa minyak kemiri sunan memiliki kadar asam lemak 
yang tinggi yaitu sebesar 9,1517\%, sedangkan bahan baku untuk proses transesterifikasi dengan katalis natrium silikat harus memiliki nilai toleransi angka asam lemak bebas $<2,5 \%$. Sehingga perlunya dilakukan pretreatment minyak dengan proses esterifikasi.

\section{Preparasi Katalis}

Pada percobaan ini natrium silikat diaktivasi terlebih dahulu dengan kalsinasi pada suhu tinggi. Berdasarkan penelitian yang dilakukan Guo dkk (2010) kondisi optimum proses kalsinasi natrium silikat diperoleh pada suhu $400^{\circ} \mathrm{C}$ dan waktu 2 jam. Dimana dengan proses kalsinasi dapat memperbaiki struktur dari katalis menjadi lebih teratur sehingga sisi aktif katalis dapat dimanfaatkan dalam proses transesterifikasi [12]. Hasil analisa dengan AAS didapatkan bahwa kandungan natrium dalam natrium silikat terkalsinasi adalah sebesar 20,7934\% dimana mempunyai kemampuan untuk mengkatalitik reaksi transesterifikasi.

\section{Pre-Treatment Minyak Kemiri Sunan}

Pada percobaan ini dilakukan perlakuan awal yaitu esterifikasi pada minyak kemiri sunan dengan kondisi optimum S.G Bojan dan S.K Durairaj [24]. Adapun tujuan dilakukan esterifikasi adalah untuk menurunkan angka asam lemak bebas pada minyak kemiri sunan.

\section{Tabel 3. Karakteristik Minyak Hasil}

\section{Esterifikasi}

\begin{tabular}{|c|c|}
\hline Parameter & Jumlah \\
\hline FFA & $1,0538 \%$ \\
Kadar air & $1,173 \%$ \\
\hline
\end{tabular}

Bahan baku untuk proses transesterifikasi dengan katalis natrium silikat harus memiliki angka asam lemak bebas < 2,5\% [11]. Jika kadar asam lemak bebas tinggi akan mengakibatkan reaksi transesterifikasi terganggu akibat terjadinya reaksi penyabunan antara katalis dengan asam lemak bebas sehingga menurunkan yield metil ester [20].

Berdasarkan hasil analisa bahan baku seperti yang terlihat pada tabel 3, didapat angka asam lemak bebas minyak kemiri sunan sebelum dilakukan esterfikasi yaitu 9,1517\%, setelah esterifikasi didapatkan penysihan angka asam lemak sebesar $88,48 \%$ sehingga angka FFA berkurang menjadi 1,0538\% . Kadar air bahan baku juga harus dikontrol secukupnya untuk menghindari pembentukan sabun. Dimana pada penelitan didapat kadar air sebesar $1,173 \%$ dimana denga katalis natrium silikat terdapat toleransi kadar air sebesar 4\% [11]. Dengan demikian, hasil esterifikasi dapat dilanjutkan ke dalam proses transesterifikasi karena angka asam lemak bebas $<2,5$ dan kadar air $<4 \%$.

\section{Proses Transesterifikasi \\ Pengaruh Suhu Reaksi}

Penelitian dilakukan pada variasi suhu reaksi dari 30,40 , dan $50^{\circ} \mathrm{C}$ dengan variasi jumlah katalis 3\% dari minyak, jumlah co-solvent $20 \%$ dari minyak dengan waktu reaksi selama 30 menit. Gambar 1 menunjukkan hubungan antara suhu reaksi terhadap yield metil ester.

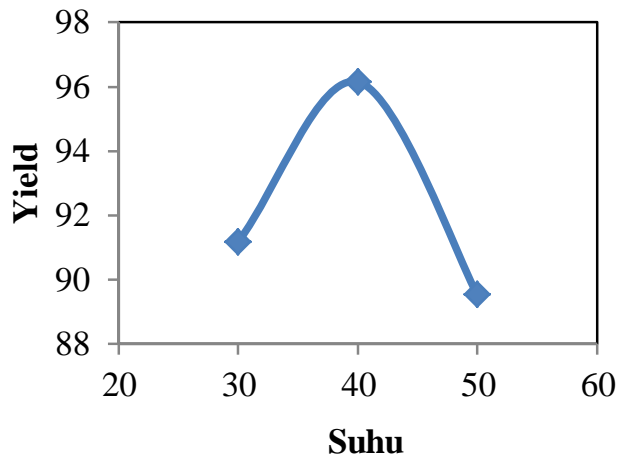

Gambar 1. Pengaruh Suhu Reaksi Terhadap Yield Metil Ester

Hasil penelitian diperoleh terlihat bahwa pada suhu $30^{\circ} \mathrm{C}$ proses transesterifikasi berjalan dengan baik dimana yield yang diperoleh lebih dari $90 \%$ dan meningkat hingga suhu $40^{\circ} \mathrm{C}$. Namun pada suhu yang terlalu tinggi terjadinya penurunan yield. Hal ini disebabkan suhu yang tinggi memacu terjadinya penguapan aseton [17].

Penelitian ini sesuai dengan penelitian Phuong Duc Lu (2014) dimana suhu optimum dari pembuaatn metil ester dengan co-solvent aseton adalah pada suhu $40^{\circ} \mathrm{C}$ namun dengan bahan baku minyak jarak [21].

\section{Pengaruh waktu Reaksi}

Penelitian dilakukan pada variasi waktu reaksi dari 10, 30, dan 50 menit dengan jumlah katalis 3\% dari minyak, jumlah cosolvent $20 \%$ dari minyak dengan suhu reaksi selama $40^{\circ} \mathrm{C}$. Gambar 2 menunjukkan hubungan antara waktu reaksi terhadap yield metil ester.

Waktu reaksi merupakan parameter penting dalam produksi metil ester. Waktu reaksi yang lebih lama akan meningkatkan yield metil ester [27]. Dimana dapat semakin lama waktu reaksi maka kontak antara minyak, metanol dan katalis menjadi lebih lama sehingga dapat meningkatkan yield dari metil ester. 


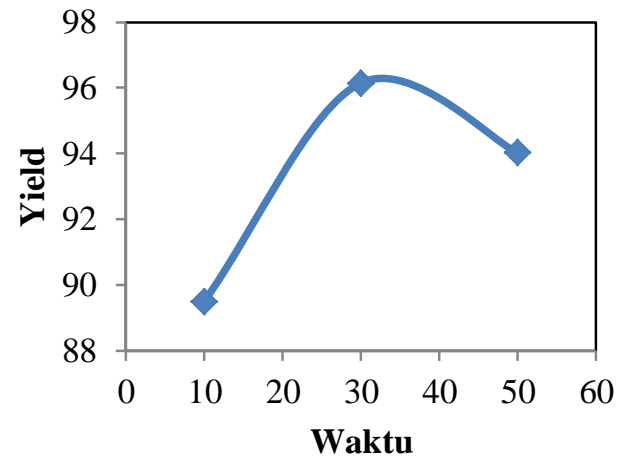

\section{Gambar 2. Pengaruh Waktu Reaksi Terhadap Yield Metil Ester}

Waktu reaksi yang optimum terdapat pada menit ke-30 dengan yield sebesar 96,1493\% dimana penambahana waktu yang terlalu panjang dapat menurunkan yield metil ester. Hal ini disebabkan oleh transesterifikasi yang merupakan reaksi reversible sehingga saat reaksi sudah mencapai keadaan optimum maka reaksi akan bergeser kekiri sehingga memperkecil pembentukan produk [24].

\section{Pengaruh Jumlah Katalis}

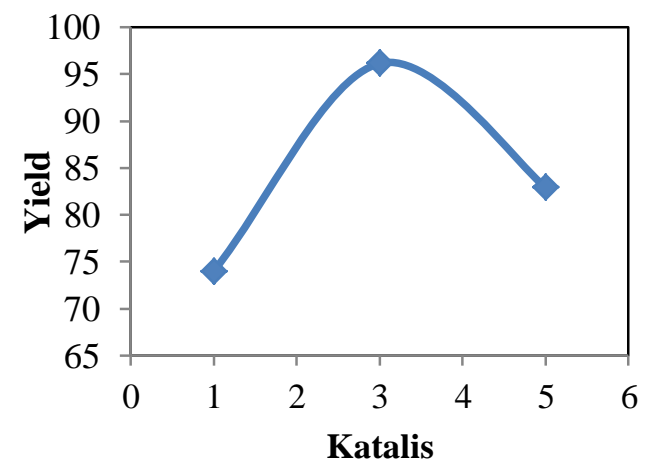

Gambar 3. Pengaruh Jumlah Katalis Terhadap Yield Metil Ester

Penelitian dilakukan pada variasi jumlah katalis dari 1, 3, dan 5\% berat minyak dengan jumlah waktu reaksi 30 menit, jumlah co-solvent $20 \%$ dari minyak dengan suhu reaksi selama $40^{\circ} \mathrm{C}$. Gambar 3 menunjukkan hubungan antara jumlah katalis terhadap yield metil ester

Jumlah katalis dapat mempengaruhi yield biodiesel. Ketika jumlah katalis ditingkatkan maka konversi trigliserida dan yield metil esterl akan meningkat juga. Kekurangan jumlah katalis akan menyebabkan konversi trigliserida menjadi ester asam lemak tidak sempurna [20].

Wilson et al (2014) menyatakan bahwa Campuran reaksi yang memiliki viskositas yang tinggi akan memberikan hasil difusi massa yang buruk dalam sistem metanolminyak-katalis heterogen yang akan memacu pengurangan yield dalam produksi metil ester [28]. Dari penelitian dapat dilihat bahwa penggunaan katalis terbaik pada pemakaian 3\% dari bahan baku. Hasil penelitian ini sesuai dengan yang dilaporkan Guo dkk (2010), tetapi menggunakan bahan baku minyak kedelai [12].

\section{Pengaruh Jumlah Co-solvent}

Penelitian dilakukan pada variasi jumlah katalis dari 10, 20, dan 30\% berat minyak dengan jumlah waktu reaksi 30 menit, jumlah katalis 3\% dari minyak dengan suhu reaksi selama $40^{\circ} \mathrm{C}$. Gambar 4 menunjukkan hubungan antara jumlah katalis terhadap yield metil ester.

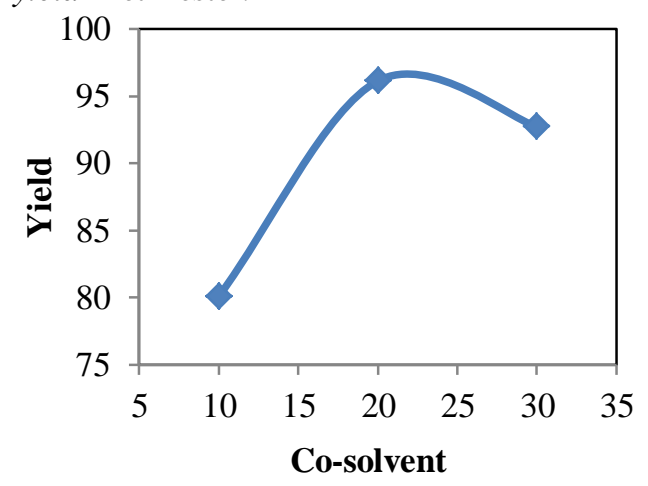

Gambar 4. Pengaruh Jumlah Co-solvent Terhadap Yield Metil Ester

Pengunaan co-solvent terbaik adalah pada $20 \%$ dari berat minyak dimana yield yang dihasilkan mencapai 96,1493\%. Penggunaan co-solvent dalam reaksi meningkatkan laju konversi minyak menjadi metil ester seiring bertambahnya waktu walaupun dalam jumlah yang sedikit [7]. Namun penambahan cosolvent secara berlebih dalam reaksi dapat menurunkan yield metil ester [16].

\section{Efektifitas Co-solvent}

Penelitian ini dilakukan dengan membandingkan kinerja transesterifikasi dengan dan tanpa co-solvent pada jumlah katalis 3\%, waktu reaksi 30 menit dan suhu $40^{\circ} \mathrm{C}$. Gambar 5 menunjukan hubungan antara komposisi metil ester terhadap co-solvent.

Pada penelitian didapatkan bahwa reaksi transesterifikasi dengan mengunakan coslovent didapatkan efektifitas yang tinggi yang lebih baik dari reaksi tanpa co-solvent. Dalam reaksi terlihat bahwa aseton bekerja efektif dalam melarutkan antara minyak dan metanol. Hal ini dapat dilihat pada koversi minyak yang mencapai $98,5641 \%$ dan terkonversinya semua trigliserida menjadi metal ester, DG dan MG. Sedangkan tanpa menggunakan co-solvent konversi reaksi yang dihasilkan hanya dapat mencapai $83,7059 \%$ 
dimana masih banyak kandungan TG,MG dan DG yang tersisa pada waktu reaksi 30 menit.

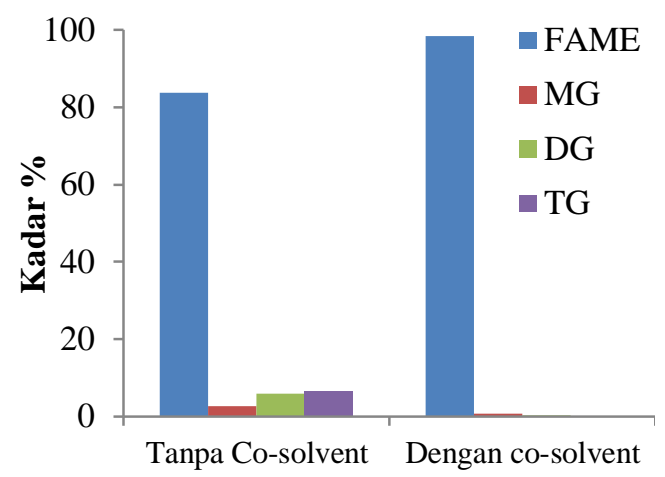

\section{Gambar 5. Komposisis Biodiesel Dengan dan Tanpa Co-solvent}

Hal ini dikarenakan pada pembuatan biodiesel tanpa co-solvent minyak dan metanol belum melarut sempurna sedangkan pada reaksi mengunakan co-solvent trigliserida yang bersifat non polar akan diikat oleh aseton yang memiliki kepolaran menengah sehingga dapat melarut baik dalam metanol yang memiliki kepolaran tinggi [19].

\section{Karakteristik FAME Minyak Kemiri Sunan}

Berikut ini merupakan tabel sifat-sifat fisika dan kimia fatty acid metil ester (FAME) Minyak kemiri sunan yang memiliki nilai Yield tertinggi sebesr 96,1493 dengan pengunaan co-solvent sebesar $20 \%$, jumlah katalis $3 \%$, waktu 30 menit dan suhu $40^{\circ} \mathrm{C}$.

\section{Tabel 4 Karakteristik FAME [26,23 ]}

\begin{tabular}{|l|l|l|l|}
\hline Parameter & Nilai & Standar & $\begin{array}{c}\text { Acu- } \\
\text { an }\end{array}$ \\
\hline Densitas & 872,68 & $850-890$ & SNI \\
Viskositas & 5,3105 & $2,3-6,0$ & SNI \\
Acid Value & 0,41 & Max. 0,6 & SNI \\
Iodine Value & 87,1477 & Max.115 & SNI \\
Kadar ester & 98,5641 & Min.96,5 & SNI \\
Kadar TG & - & Max.0,2 & EN \\
Kadar DG & 0,0857 & Max.0,2 & EN \\
Kadar MG & 0,7036 & Max.0,8 & EN \\
& & & \\
\hline
\end{tabular}

Dapat dilihat pada table 4 bahwa dari densitas, viskositas kinematik, bilangan asam, bilangan iodin, kandungan ester, trigliserida, digliserida dan monogliserida pada metil ester dari minyak kemiri sunan telah memenuhi syarat SNI maupun EN dan dapat disimpulkan bahwa metil ester yang dihasilkan pada kondisi yang baik.

\section{Kesimpulan}

Dari hasil penelitian dapat disimpulkan bahwa pengunaan aseton memiliki efektifitas yang tinggi sebagai co-solvent dalam proses transesterifikasi dengan menggunakan katalis heterogen natrium silikat. Pada penelitian ini, kondisi terbaik untuk proses pembuatan metil ester adalah dengan penggunaan katalis sebanyak 3\% dari minyak, Jumlah co-solvent $20 \%$ dari minyak dengan waktu reaksi 30 menit dan suhu reaksi $40^{\circ} \mathrm{C}$. dimana didapatkan yield sebesaar 96,1493\%. Karakteristik biodiesel yang dihasilkan telah memenuhi standart SNI maupun EN dari segi densitas, viskositas, bilangan asam, bilangan iodin, kandungan metil ester, trigliserida, digliserida dan monogliserida.

\section{Daftar Pustaka}

[1] A.M. Ashraful, H.H. Masjuki, M.A. Kalam, I.M. Rizwanul Fattah, S. Imtenan, S.A. Shahir dan H.M. Mobarak, "Production and comparison of fuel properties, engine performance, and emission characteristics of biodiesel from various non-edible vegetable oils: A review," Energy Conversion and Management, 80(2014), 202-228.

[2] A. Wahyudi, Y. Ferry, M. Herman, D. Pranowo dan K. Ardana, "Proyeksi Produksi Biodiesel," Buletin Balitri, 2009: hal. 119-126.

[3] A. Aunillah dan D. Pranowo, "Karakteristik Biodiesel Kemiri Sunan [Reutealis trisperma (Blanco) Airy Shaw] Mengunakan Proses Transeterifikasi Dua Tahap," Buletin RISTRI, 3(3) 2012, 193-200.

[4] ASTM D 1959, Standart Method for iodine value of drying oil and fatty acid, 2006.

[5] ASTM D 445, Vscosity of transparent and opaque liquid, 1965.

[6] C. Martı'n, A.Moure, G. Martı'n, E. Carrillo, H. Domı'nguez dan J. C. Parajo, "Fractional characterisation of jatropha, neem, moringa, trisperma, castor and candlenut seeds as potential feedstocks for biodiesel production in Cuba," biomass and bioenergy, 34(2010): hal. 533-538.

[7] C. Lin dan M. Hsiao, "Optimization of Biodiesel Production from Waste Vegetables Oil Assisted by Co-solvent and Microwave Using a Two-Step Process". Journal of Sustainable Bioenergy Systems, 3, 2013 : hal. 1 - 6.

[8] D. Pranowo et al, Pembuatan Biodiesel Dari Kemiri Sunana Dan Pemanfaatan 
Hasil Samping (IAARD Press, 2014), hal. 32

[9] E. D. C. Sidabutar, M. N. Faniudin dan M. Said, "Pengaruh Rasio Reaktan Dan Jumlah Katalis Terhadap Konversi Minyak Jagung Menjadi Metal Ester," Jurnal Teknik Kimia, 19(1) 2013, 40-49.

[10] E. Setiawati dan F. Edwar, "Teknologi Pengolahan Biodiesel Dari Minyak Goreng Bekas Dengan Teknik Mikrofiltrasi Dan Transesterifikasi Sebagai Alternatif Bahan Bakar Mesin Diesel," Jurnal Riset Industri, 6(2) 2012: hal. 117-127.

[11] F. Guo, N. Wei , Z. Xiu dan Z. Fang, "Transesterification mechanism of soybean oil to biodiesel catalyzed by calcined sodium silicate," Fuel, 93(2013): hal 468-472.

[12] F. Guo, Z. Peng, J. Dai dan Z. Xiu, "Calcined sodium silicate as solid base catalyst for biodiesel production," Fuel Processing Technology, 91(2010): hal. 322-328.

[13] H.V. Lee, R. Yunus, J.C. Juan, Y.H. Taufiq-Yap, "Process optimization design for jatropha-based biodiesel production using response surface methodology," Fuel Processing Technology, 92(2011) : hal. 2420-2428.

[14] ISO 3500-1999, laboratory glassware pkynometer, newdelhi.

[15] ISO 660-1996/AMD1.2003, Determination acid value and acidity, Switzerland.

[16] L. M. Kee, K. T. Lee, dan A. F. Mohamed, "Homogeneous, Heteregeneous, and Enzymatic Catalyst for Transesterification of High Free Fatty Acid Oil (Waste Cooking Oil) to Biodiesel : A Review". Biotechnology Advances, 28, 2010 : hal. $300-318$.

[17] L. T. Thanh, K. Okitsu, Y. Sadanaga, N. Takenaka, Y. Maeda, dan H. Bandow, "A New Co-Solvent Method for The Green Production of Biodiesel Fuel Optimization and Practical Application". Fuel, 103(2013) : hal. 742 - 748.

[18] M. Herman dan D. Pranowo, "Karakteristik Buah dan Minyak Kemiri Sunan (Reutealis trisperma (Blanco) Airy Shaw)," Buletin Ristri, 2(1) 2010: 21-28.

[19] O.Rachmaniah, A. Baidawi, dan I. Latif, "Produksi Biodiesel Berkemurnian Tinggi dari Crude Palm Oil (CPO) dengan Tetrahidrofuran-Fast Single-
Phase Process". Reaktor, 12 (3) 2009 : hal. $166-174$.

[20] O. W. N. N. Wan dan A. N. A. Saidina., Optimization of Heterogeneous Biodiesel Production from Waste Cooking Palm Oil Via Response Surface Methodology, Biomass and Bioenergy, 35 (1329-1338), Elsevier, 2011.

[21] P. D. Luu, H. T. Truong, B. V. Luu, L. N. Pham, K. Imamura, N. Takenaka dan Y. Maeda, "Production of biodiesel from Vietnamese Jatropha curcas oil by a cosolvent method," Bioresource Technology, 173(2014): 309-316.

[22] P. Setyopratomo, E. Purwanto, R. Hartanto, dan J. Kristianto, "Pengaruh Suhu Reaksi dan Rasio CPO/Metanol terhadap Karakteristik Produk pada Pembuatan Biodiesel dengan Co-Solvent Dietil Eter". Jurnal Ilmu Dasar, 9 (1) 2008 : hal. 72-77.

[23] R. S. Kumar, K. Sureshkumar, R. Velraj, "Optimization of biodiesel production from Manilkara zapota (L.) seed oil using Taguchi method" Fuel, 140 (2015): hal.90-96

[24] S.G. Bojan dan S.K Durjana, "Producing Biodiesel from High Free Fatty Acid Jatropha Curcas Oil by A Two Step Method- An Indian Case Study," Journal of Suistanable Energy \& Enviroment, 3(2012): hal. 63-66.

[24] S. Salamah, "kinetika reaksi esterifikasi minyak biji kapuk pada pembuatan biodiesel," Chemica,I(2014): hal. 11-18.

[26] SNI, "Standar dan Mutu Bahan Bakar Nabati Jenis Biodiesel sebagai Bahan Bakar Lain yang Dipasarkan di Dalam Negri”. Kementrian Energi dan Sumber Daya Mineral Republik Indonesia, Nomor : 723 K/ 10/ DJE/ 2013.

[27] T. Muppaneni, H. K. Reddy, Sundaravadivelnathan, P. D. Patil, P. Dailey dan S. Deng, "Optimization of Biodiesel Production from Palm Oil Under Supercrtical Ethanol Condition Using Hexane as Co-Solvent: A Respone Surface Methodology Approach". Fuel, 107(2013) : hal. 633640.

[28] W. W. Sheng Ho , H. Kiat Ng , S. Gan, S. H. Tan, "Evaluation of palm oil mill fly ash supported calcium oxide as a heterogeneous base catalyst in biodiesel synthesis from crude palm oil", Energy Conversion and Management, 88 (2014): hal. 1167-1178 